\title{
On the Allure of Bridges vs. Diving for Pearls:
}

A Phenomenological Inquiry into Autism and Ontological Inclusion

\author{
Glenn M. Hudak \\ University of North Carolina at Greensboro
}

In the study, "More on the Ontological Status of Autism and Double Empathy," Nicholas Chown speculates on the implications of the "double empathy" hypothesis: namely, that "non-autistic people appear to have as much difficulty in understanding autistic minds as vice versa." In an effort to unpack the subtlety of double empathy, Chown devises a clever thought experiment: he speculates that in any given society, about " $1 \%$ of any population is autistic and $99 \%$ is non-autistic."' Given this statistic, what would happen if the tables were turned, so to speak? That is, he asks us to imagine a hypothetical world that is comprised of $99 \%$ autistic people and $1 \%$ non-autistic. Next he asks, in such a world would autistic persons have as much difficulty understanding non-autistic people as non-autistic people in our society have in understanding the minds of autistic people? That is, how would a non-autistic person, in this hypothetical society, come to understand the world of the dominant autistic population, given its autistic-centered language, society, and institutions?

It is not possible to articulate the full scenario that Chown devises here, but his conclusions are quite interesting:

In other words, non-autistic people would be no better off in the hypothetical world than autistic people in the actual world. This would mean that the ontological status of both autistic and non-autistic neurotypes is partly dependent upon the nature of society. We might want to say that the ontological status is socially constructed to this extent... [that] in the world we live in [our current world], the public criteria available to members of society for purposes of imputing mental states are by definition, public criteria of a fundamentally non-autistic ontological state. ${ }^{3}$ 
The takeaway from Chown's study is that neither the autistic nor the non-autistic worldview has ontological priority over the other. Put another way, the dominance of the non-autistic worldview, the one in which we live in, has no ontological priority over the marginalized autistic worldview; rather, the status given to the non-autistic worldview is "dependent upon the nature of society" we live in. Hence difference in status is not ontological difference per se but societal, or political in terms of unequal representation within the public domain, difference in terms of interlocking practices, equipment, and skills used and relied upon in daily life. The rub however is that given all this, each worldview is the "same" with regards to their respective ontological status: each worldview carries equal weight, so to speak, as neither worldview has the last word on the "truth" of being, of existence. Neither worldview has a monopoly on defining the nature of reality, ontologically.

The problem for Chown is precisely that, "There are no public criteria of an autistic ontological state to assist the non-autistic to understand the autistic." ${ }^{4}$ Consequently the implications for autistic people are that they cannot expect to find much sympathetic support or understanding within the predominately non-autistic society they live in, as perspectives reflecting an autistic ontology are largely absent from the public domain. Indeed, Chown emphasizes that despite this situation those autistic people who do survive in this "hostile world" are those who use "their intellectual prowess to hack out an understanding of other minds... as they have little choice in the matter." ${ }^{5}$

Significantly here is Chown's choice of words to describe autistic people's struggles within the dominant neurotypical-centric world as having "to hack out an understanding of other minds." Autistic writer (then 13 years old) Naoki Higashida in The Reason I Jump attempts to "hack out" an understanding of the neurotypical mind when he asks his readers to explore with him about the origins of autism: where does autism come from? He responds:

I can't help but feel that some imbalance in this world first caused neuro-atypical people to be needed and then brought into being... [As such], I refuse to accept it when people view us as incomplete or partial beings; I prefer to believe that people with autism are every bit as whole 
as everyone else. We might be different from the majority in diverse ways, but why are those differences negative things. ${ }^{6}$

This quote from Higashida reinforces Chown's claims regarding the equal weight of autistic being-in-the-world with the neurotypical view as autistics are "every bit as whole as everyone else," and at the same time Higashida alerts the reader of his struggle to "hack out" an understanding as to why autistic differences are viewed as negative.

One aspect of Higashida's hacking out an understanding of the nonautistic mind is to address persistent myths regarding autism. One myth is that autistic people are "locking themselves up inside themselves." Higashida's response is that if autistic people were truly locked within themselves then "we wouldn't be coming out with our weird utterances or be prone to panic attacks. I take these phenomena as proof that our emotions exist and are trying to exhibit themselves." In short, while the non-autistic world overwhelms in its pervasiveness, it doesn't contain efforts by autistic philosophers to bring an autistic ontology. Indeed, the "neurotypical public needs to know that the failure of people with autism to communicate doesn't stem from inner selfimprisonment: it stems from a failure of others to see that we are open and receptive. To venture out into the world requires help from other people. Please lend us that support as we strive to live in society."

Here, Higashida does not simply tell the neurotypical world about autism, or about its misconceptions and myths; he extends himself through the writing process itself to educate the reader. Indeed, his response demands that he become a writer, where he has to create what Vivian Gornick refers to as creating one's own "writing persona"-a narrator and truth teller who provides the insight of the story told. For Gornick a work of non-fiction writing has both a situation and a story: "The situation is the context or circumstance; the story is the emotional experience that preoccupies the writer: the insight, the wisdom, the thing one has come to say," where the situation is Higashida clarifying neurotypical misconceptions about autistic people. ${ }^{10}$ To get to the story line, the wisdom the reader comes looking for, Higashida creates a narrative persona who brings the situation together into a coherent picture. In 
constituting this persona Higashida's writing takes on the pedagogical act of instructing his audience as he asks, "Please lend us that support as we strive to live." Here Higashida doesn't simply want neurotypical sympathy; instead he aims to instruct on how neurotypicals can be helpful. In this way, we can see how he tacitly takes up the double empathy hypothesis by providing the non-autistic world with the beginnings of an autistic ontology and in this process becoming an ontological subject himself whose point of view educates his reader-hence he is someone worth listening to. As such, his response to neurotypical readers moves beyond presenting mere knowledge and information.

As a writer Higashida educates his reader by bridging the gap between autistic and non-autistic understanding by providing insights into autistic thinking. Higashida writes,

Because we can't talk, it's kind of inevitable that we can't make our innermost feelings known easily, if at all. That might be the sad reality, but I don't think it calls for despair. Why? Because we 'nonverbals' have a friend who lives inside us. Inhabiting my mind is a person who is Me and who isn't Me. I talk to my other me as if he were an old friend, both when I'm happy and when I'm sad. That is why it's especially important never to hate ourselves. Once you start hating your self, this old companion draws away... [So]... Please go ahead and tell us nonverbals "I like you" or "I love you" whenever the fancy takes you. When someone tells you that it become a whole lot easier to like yourself. ${ }^{11}$

Here we find Higashida referring to his inner world of thinking, which sounds remarkably similar to Hannah Arendt's, “'The Two-in-One." Here Higashida and Arendt observe the duality in thinking between me and yet not me in one's inner dialogue with oneself. Here, too, we note for both the only requirement for thinking in Arendt's terms: being a friend to one's self. And here we note how both talk to an old friend, who again in Arendtian terms would be one's conscience, for advice.

In both his writing on autistic ontology and his teaching of the non- 
autistic reader, Higashida relies on a word processor to communicate his thoughts. Indeed, Higashida's engagement with the internet seems to support a claim made by Ian Hacking: "Neurotypical and severely autistic people do not initially share a form of life because the bedrock is lacking, and so an artificial platform must be constructed... In retrospect, we shall certainly see today's internet as making possible a form of life in which autistic people can thrive. It is precisely the medium for human communication that does not depend on body language or eye contact..."12 Here as Hacking metaphorically suggests, the internet works as a bridge connecting the autistic and the non-autistic worldviews. I call this alluring metaphor "Hacking's Bridge," as the thrust of Hacking's thinking is that the internet affords nonverbals, like Higashida, an opportunity to "hack away" (no pun intended) at the wall of mutual non-understanding revealed by the double empathy hypothesis - that is, to hack away at the difficulty autistic and non-autistic people have understanding the other's worldview. Here the internet, in the sense of Hacking's bridge metaphor, is a revelation in that it allows mutual revealing, a disclosing of worldviews, and hence some "bedrock" to ground a conversation between writers expressing different worldviews.

Hacking's Bridge suggests the possibility of a moment of "ontological inclusion" whereby traditional ontology is open to exposure from an autistic worldview and vice versa. Is such a moment of inclusion a happening, an event of coming-together? If so, does this coming-together signal that the divide between autistic and non-autistic people with regard to the double empathy hypothesis is beginning to lessen? That is, as conversations between autistic and non-autistic people occur on Hacking's Bridge, will greater mutual understanding ensue?

It is certainly plausible that a moment of inclusion can occur, especially as Gert Biesta posits a sort of inclusion whereby inclusion embraces "what cannot be know to be excluded in terms of the existing order, [and hence] the inclusion of what I referred to as the incalculable."'13 Here Biesta views the incalculable as a unique event outside the existing order such that it transforms the existing order in a fundamental way. That is, by bringing autistics and nonautistics into proximity the unexpected can happen: an unexpected encounter that fundamentally transforms their relationship to each other: indeed, a 
transformation of such unexpected proportions that when viewed from the perspective of our current thinking about autism, this moment of inclusion appears as Biesta claims, to be incalculable. This unexpected transformation of autistics and non-autistics is certainly a very worthwhile hope. For as Higashida poignantly declares, "And when the light of hope shines on all the world, then our future will be connected with your future. That's what I want, above all else."14

Hopefulness aside, Higashida's declaration, "then our future will be connected with your future," is somewhat vague in that it does not clarify how such ontological inclusion is to happen. Hypothetically then, we might consider three options of ontological inclusion, where each option specifies movement and direction between worldviews. One option would be to consider how the autistic worldview moves in the direction of the dominant neurotypical-centered worldview. A second option to consider is where each worldview meets on Hacking's Bridge to converse. Regarding the third option, we might consider how the dominant neurotypical-centered worldview moves towards an autistic worldview.

Regarding the first option, where ontological inclusion occurs as the marginalized worldview moves towards the dominant worldview, this seems a quite realistic scenario. Indeed, in Rancière's Disagreement, for example, he illustrates how the Roman plebeians have to be first "seen" by the Roman senate to be-to be seen as a subject worthy of consideration for better or worse. ${ }^{15}$ Here the plebeian worldview is drawn into and ruptures the dominant world order. To a certain extent Higashida's writing efforts reflect this move, in that in order for him to be listened to by the dominant order, he has to be noticed as a subject worthy of consideration by the non-autistic worldview. Here the plebeians and Higashida rupture the dominant order, the order of the sensible, as they are included within the dominant order in moving from the margins to the center.

What of the second option: the two worldviews meeting on Hacking's Bridge? In the recent text by Joris Vlieghe and Piotr Zamojski, the authors affirm and clarify Arendt's claim that education is an realm autonomous from politics. ${ }^{16}$ Here and with regard to ontological inclusion, the meeting on Hacking's Bridge takes place within an educational space that is "bracketed off" from 
the political. Hence the bridging, the meeting of worldviews, occurs within an autonomous space whereby the main thrust of this study comes into focus: a thing-centered pedagogy. For them the thing has special meaning, as the "thing" becomes both the focal point of the pedagogical engagement between the students and teacher, as well as the focusing of all relevant activities within the pedagogical engagement. As such, the thing is both the object of attention and the source of gathering one's attention around that object at hand-hence a thing-centered pedagogy.

As the thing "things," it acts to gather together people into local worlds, places where people have a common focal point that centers their interactions and their attention. An example is a laboratory table that gathers together people, equipment, and activities for science experiments such that it affords participants with a sense of centeredness expressing who they are within the context of their local world of the lab experiment: students and teacher engaged in study. For Vlieghe and Zamojski (and Heidegger) things, then, are not objects. An object is a fixed fact that doesn't instigate one's attention; a spoon is an object to be used, until it becomes a thing: "a source of questions that strike us as thought-provoking... a thing withdraws... affects us, and therefore, inevitably—we could add—-makes us attentive... And hence: things withdraw... [in that] it is precisely the withdrawal of a thing that draws us towards it." ${ }^{17}$ It is the thing in its withdrawal that provokes our thought; in other words, as thought is provoked it follows the thing's withdrawal as an act of study as it simultaneously gathers, brings-together, and appropriates the classroom into an educational world. As such,

A thing brings people together because it divides them. This means that a thing makes people equal without overcoming or abolishing their diversity... Those gathered around a thing differ in the claims they make about the thing, in the way they investigate it, in the way they connect with it to previous understanding, etc. The gathered are plural, not one, and simultaneously, they are equal, i.e., the Same is relation to the thing of study. ${ }^{18}$

Key to Vlieghe and Zamojski's explication of the thing-centered 
pedagogy is the rather emphatic claim: "It must be emphasized here that we speak of the world, not of worlds... from an educationalpoint of view, there can only be one world. The world is that what is given, that what is out there and in which we are all born." ${ }^{19}$ That is, ontologically speaking there may be descriptions of alternative worlds, but no matter, for one world is always given, and only one world. Hence, we may posit a "one-world hypothesis" at play here.

From an educational point of view then, a one-world hypothesis would assert that no matter how many local worldviews may exist in the classroom, when the student and teacher are engaged by the thing, both are drawn into an educational space that claims their immediate attention, forming one educational world. Hence, for a thing-centered pedagogy it is the thing in its "thinging" that claims the attention of teacher and students alike, hence bridging-together worldviews within one world for study. As such, given that there is one educational world which is given through the thinging of things as it gathers together distinct worldviews within the educational context, then it is also easy to see how the thing-centered pedagogy satisfies option number two: two worldviews meeting. But what of Hacking's Bridge? Given the thing-centered orientation discussed, there is no conceptual reason to deny the internet the status of a "thing" in the classroom. Indeed, utilizing Hacking's Bridge affords the teacher a hybrid educational space for gathering where the autistic and the non-autistic students can meet, mingle, and gather together, albeit "without overcoming or abolishing their diversity." 20

In sum, the one-world hypothesis seems obvious from an educational perspective — as in, there is only one world - however, what's occluded by this claim is that the one-world hypothesis asserts authority over all ontological accounts of education. What's occluded here is that not everything that is educational is accountable under the term "educational": for example, the non-educational, as an educational concern! To address this issue, we now turn to the third option for ontological inclusion.

Indeed, option number three is sensitive, as ontological inclusion indicates "movement" from the dominant neurotypical-centered to the autistic worldview. It is sensitive because the movement from dominant to autistic worldview can be an act of inclusive colonization or what Biesta refers to as 
“imperialistic expansion." ${ }^{21}$ Leaving aside this caution, option three also opens up unexpected insights precisely into the non-educational by abandoning, temporarily, the allure of Hacking's Bridge for diving for pearls. How so? Let's return to Higashida's writing on autistic ontology, where he declares, "I think people with autism are born outside the regime of civilization... we are more like travelers from a distant, distant past. And if, by our being here, we could help the people of the world remember what truly matters for the Earth, that would give us a quiet pleasure." ${ }^{22}$ I do not interpret Higashida here to be making a sort of nostalgic request for the "good old days." Rather, for me, he is suggesting something quite profound, in that not only have we, neurotypical, forgotten something important for humanity's survival, but further, autism may hold the key to disclosing what "truly matters" for Earth.

Here we may say that autism has in its possession something of great importance for the earth. Here one might read this as an invitation into the house of autism, so to speak. The real concern here is how to proceed in this house when, as Chown has stated earlier, "There are no public criteria of an autistic ontological state to assist the non-autistic to understand the autistic." ${ }^{23}$ For me, when I free associate an autistic traveler from a distant, distant past, I'm reminded of Arendt's characterization of Walter Benjamin's thinking as "pearl diving." Perhaps Higashida's notion of bringing back something from a distant past is akin to an autistic pearl diver. If so, his neurotypical counterpart is Fernand Deligny (1913-1996). If Higashida dives into neurotypical waters to retrieve something that "truly matters" to earth, then Deligny attempts to dive into autistic waters to bring up an autistic pearl. Here both seem to prefer diving to bridges!

During the late 1960s Deligny established an experimental center in mountainous rural France, "a raft in the mountains," to work with autistic children who had no place to live, either being abandoned by their parents or unable to be wards of the state. "All of the children are profoundly autistic, mute," as the children could not (or as Deligny suggests did not want to) speak. ${ }^{25}$ The adults who "permanently watch over the children day and night" are called 'the close presences.' One day in 1969 a 'close presence' expressed his fear of seeing children bite themselves and bang their foreheads against 
stones." ${ }^{26}$ As opposed to speculating over the actions of the children, Deligny suggested to this close presence that he instead draw a map of the child's route through the center's living area, thereby tracing the child's daily journey through the camp.

These maps and their tracings in turn came to serve as logs, a form of nonverbal narration of daily life in the camp. Deligny observed, "As I kept filing [the tracings] away on top of each other, one day to my bewilderment, I realized that the wander lines never went out of a sort of circle." ${ }^{27}$ While these wander lines, as Deligny calls the child's journeys, through the living area appeared random, there was nonetheless a pattern. However, since Deligny didn't "know what the children want, and since asking them for a response in the realm of wanting manifestly constitutes a form of violence towards them, [perhaps then] let's look instead at what they do. Let's look at them indirectly, by way of their journeys, instead of imposing on them an intersubjective face-to-face encounter." ${ }^{28}$ Deligny's intent, then, is to avoid discernments about the children, such as what the patterns mean. In doing so he is engaging in the radical un-doing of power imposed by institutions, such as the power to diagnosis autistic children.

What Deligny found out was that the maps and tracings create a:

sort of choreographic investigation or provocation, [where] paths and journeys, roamings and routes interweave until shared dances, trivial and sublime, unpredictably appear around the most basic and essential gestures of life. Little by little, the autistic children join the common activities... The fact that they are shared, carried out in common, does not mean that they are identical. Washing, preparing, planning, cutting, cooking, distributing, collecting... Deligny goes so far as to refuse to name what is happening then... in a decision to leave the door that was just passed through wide open, not reducing it to progress, healing, or an "exit from autism"... [this] enables him to leave the matter unresolved. ${ }^{29}$

Within this unresolved situation it is not hard to imagine Deligny 
trying to catch what continuously withdraws from his grasp while at the same time trying to refrain from theorizing a very thought-provoking situation to avoid further violence on the children. Here we come face to face with an unstated tension within the thing-centered pedagogy and the allure of Hacking's (internet) Bridge: a tension located within the mundane acts of living concretely within an educational space.

We might call this network that forms itself without wanting to be formed the mundane. Indeed, Deligny leaves this network to form itself such that the mundane can occur, and where the adults perform a dance, without intending to dance with the children. As such within this mundane Deligny hopes the children find "serenity, a kind of happiness, autonomy, a cruising speed through sentient life that would be difficult to find in the institutions that seek to be, with the best of intentions in the 'world' (our own), pedagogical, educational, and therapeutic." 30 Deligny's efforts are not focused on theorizing the autistic child, nor about the child becoming a subject; rather he seeks-without-seeking a sort of de-subjectification whereby the child is free to extend their body in the mundane of the living area. As such, "The political is no longer an intersubjectivity issue of the relationship with the other, but rather a co-presence issue whose articulation is infinite, never-ending task... the invention of a novel non-educational, non-therapeutic, spatial, and behavioral apparatus..."31 The issue for Deligny is not one of the educational: the continuous relationship with the thing (and the internet) as center, drawing upon the student and teacher's attention as an educational moment. Rather, Deligny's intent revolves around the non-educational; it is to liberate the autistic child's attention from the thing to things in her everyday world, the mundane that falls below the educational radar. As such, we find non-intentional dances vital to the formation of the network as they appear to have no purpose-in short, the non-educational moment.

What about Deligny? Deligny is aware that he speaks a language that is perhaps not that of the children, hence his struggle is to see the child in such a fashion that allows the child "to exist in their own singular way without their existence reduced to a psychological or educational insight."32 
In short, within Deligny's asylum there is no subject matter for study in the sense of a thing-centered pedagogy. What does Deligny retrieve from the depths of autistic waters? Autos!

Autos is the Classical Greek root for the modern word autism. ${ }^{33}$ Interestingly, autos is a mode of self-affirmation as it means of one's true self, of oneself, of one's own accord, to be with oneself among friends. ${ }^{34}$ More specifically, we can derive from autos two existential traits. First, autos entails being with oneself in the presence of others without defensiveness such that one can relax in the world, "to be among friends." Such a moment might be a child playing on the beach while her parents are reading or sleeping on lounge chairs. Here the child is lost in her own world of imaginative play; she is alone (in a very positive sense) while in the presence of another. The corollary trait derived from the first, is that autos affords one the freedom to withdraw from the everyday activities, without fear of being stigmatized, being perceived as a "loner," or pathologically self-absorbed by others as Higashida noted earlier.

In the end, Higashida and Deligny are world-disclosers. And what they are disclosing is a gesture from autism's very, very distant past: autos. This gesture is found as one abandons the bridge for the solitude of diving. What then does this gesture signify? Peace! That is, autos is the ontological condition for humans to live in peace. While the elimination of poverty and war is necessary for a peaceful world, it is not sufficient without the possibility of autos-the ontological possibility to co-exist in the same space, to breathe a common air, so to speak, while attending to the mundane.

1 Nicholas Chown, "More on the Ontological Status of Autism and Double Empathy," Disability and Society 29, no. 10 (2014): 1673.

2 Chown, 1673.

3 Chown, 1675.

4 Chown, 1675, emphasis added. 
5 Chown, 1675.

6 Naoki Higashida, The Reason I Jump (New York: Random House, 2016), 165, emphasis added.

7 Higashida, 165.

8 Higashida, 165.

9 Higashida, 165.

10 Vivian Gornick, The Situation and the Story (New York: Farrar, Straus and Giroux, 2001), 13.

11 Higashida, The Reason I Jump, 169-170.

12 Ian Hacking, “Humans, Aliens \& Autism,” Daedalus 138, no. 3 (2009): 56.

13 Gert Biesta, Good Education (Boulder: Paradigm Press, 2010), 125.

14 Higashida, The Reason I Jump, 170.

15 Jacques Ranciere, Disagreement (Minneapolis: University of Minnesota Press, 1999), 23.

16 Joris Vlieghe and Piotr Zamojski, Towards an Ontology of Teaching: Thingcentered Pedagogy, Affirmation and the Love for the World (Cham, Switzerland: Springer, 2019), 172.

17 Vlieghe and Zamojski, 60-61.

18 Vlieghe and Zamojski, 63.

19 Vlieghe and Zamojski, 28.

20 Vlieghe and Zamojski, 63.

21 Biesta, Good Education, 124.

22 Higashida, The Reason I Jump, 111.

23 Chown, "More on the Ontological Status," 1675, emphasis added.

24 Sandra Alverez de Toledo, Maps and Wander Lines, Fernand Deligny 19691979 (Paris: L'Arachneen, 2013), 6.

25 Alverez de Toledo, 6.

26 Alverez de Toledo, 5.

27 Alverez de Toledo, 7. 
28 Fernand Deligny, The Arachnean and Other Texts (Minneapolis: University of Minnesota Press, 2015), 13.

29 Alverez de Toledo, Maps and Wander Lines, 408, emphasis added.

30 Alverez de Toledo, 408.

31 Alverez de Toledo, 409, emphasis added.

32 Jan Masschelein and Pieter Verstrate, "Living in the Presence of Others: Towards a Reconfiguration of Space, Asylum, and Inclusion," International Journal of Inclusive Education 16, no. 11 (2012): 10.

33 Douglas Biklen, Autism and The Myth of the Person Alone (New York: NYU Press, 2005), 51.

34 G. Babiniotis, "Autos," in The Dictionary of Modern Greek (Athens, Greece: Lexicology Centre Publ., 1998). 